\title{
Interface band structure engineering by ferroelectric polarization in perovskite solar cells
}

\author{
Bo Chen, ${ }^{* a l}$ Xiaojia Zheng, ${ }^{a l}$ Mengjin Yang, ${ }^{b}$ Yuan Zhou, ${ }^{a}$ Souvik Kundu, ${ }^{a}$ Jian Shi, ${ }^{c}$ Kai
} Zhu, ${ }^{b}$ Shashank Priya $*^{a}$

a, Center for Energy Harvesting Materials and System, Virginia Tech, Blacksburg, Virginia 24061, United States

b, Chemical and Nanoscience Center, National Renewable Energy Laboratory, Golden, Colorado 80401, United States

c, Department of Materials Science and Engineering, Rensselaer Polytechnic Institute, Troy, New York 12180, United States

1 These authors contributed equally to this work.

Corresponding author: bochen09@vt.edu (B.C.), kai.zhu@nrel.gov (K.Z.), spriya@ vt.edu (S.P.)

\begin{abstract}
:
We demonstrate the presence of ferroelectric domains in $\mathrm{CH}_{3} \mathrm{NH}_{3} \mathrm{PbI}_{3}$ by piezoresponse force microscopy and quantify the coercive field to the switching of the polarization of ferroelectric $\mathrm{CH}_{3} \mathrm{NH}_{3} \mathrm{PbI}_{3}$. For $\mathrm{CH}_{3} \mathrm{NH}_{3} \mathrm{PbI}_{3}$ perovskite solar cell, negative electric poling decreases the net built-in electric field, driving potential and width of depletion region inside the absorber layer, which hinders charge separation and deteriorates photovoltaic performance; while positive poling boosts these electrostatic parameters and therefore improves the charge separation inside the absorber. Low coercive field $(8 \mathrm{kV} / \mathrm{cm})$ enables the switching of $\mathrm{CH}_{3} \mathrm{NH}_{3} \mathrm{PbI}_{3}$ polarization during the current density-voltage $(J-V)$ measurement. Forward scan initially activates the negative poling, whereas reverse scan first activates the positive poling, which can lead to the $J-V$ hysteretic behavior. Comparative analysis with a traditional ferroelectric $0.25 \mathrm{BaTiO}_{3}-0.75 \mathrm{BiFeO}_{3}$ solar cell is conducted to confirm the impact of ferroelectric polarization and $J-V$ scanning direction on photovoltaic performance.
\end{abstract}

Keyword: ferroelectric polarization, band structure, hysteretic behavior, organometal halide perovskite, solar cells

\section{Introduction}

Organometal halide perovskites have shown great potential for high efficiency solar energy harvesting owing to variety of factors including superior light absorption coefficient, large electron/hole diffusion lengths, and near-perfect crystallinity.[1-9] The power conversion efficiency of organometal halide perovskite solar cells has increased rapidly in the past five years and a champion efficiency of $20.1 \%$ has been reported recently.[10, 11] The typical structure for organometal halide perovskite solar cells consists of the n-type $\mathrm{TiO}_{2}$ layer as electron-transporter layer $(E T L)$, an organohalide perovskite thin layer as light absorber and the p-type spiro-MeOTAD as hole-transporter material $(H T M)$. Similar to the $p-i-n$ heterojunction solar cell, the intrinsic built-in electric field (at heterojunction $p-i$ and $i$ - $n$ interfaces) is one substantial component to drive the separation of photo-generated charges.[12-15] Though the crystal structure for organometal halide perovskite is centrosymmetric tetragonal with $\mathrm{I} / \mathrm{mcm}$ space group at room temperature,[16] ferroelectric 
domains have been observed in the methylammonium lead triiodide $\left(\mathrm{CH}_{3} \mathrm{NH}_{3} \mathrm{PbI}_{3}\right.$ or $\mathrm{MAPbI}_{3}$ ) perovskite, $[17,18]$ which can be ascribed to the reduced lattice symmetry of molecular $\mathrm{CH}_{3} \mathrm{NH}_{3}{ }^{+}$dipoles.[19] However, whether ferroelectric effect of $\mathrm{CH}_{3} \mathrm{NH}_{3} \mathrm{PbI}_{3}$ perovskite has an important impact on the photovoltaic performance remains unclear.

Photovoltaic effect has been reported in many ferroelectric materials (such as $\mathrm{BiFeO}_{3}$, $\mathrm{Pb}(\mathrm{Zr}, \mathrm{Ti}) \mathrm{O}_{3}$, and $\left.\mathrm{Bi}_{2} \mathrm{FeCrO}_{6}\right)$ with best efficiency of $8.1 \%$ for ferroelectric solar cells based on $\mathrm{Bi}_{2} \mathrm{FeCrO}_{6}$.[20-29] These ferroelectric solar cells have been proposed to utilize the polarization electric field to drive the charge separation and transport. Ferroelectric polarization electric field has also been introduced into organic solar cells to tune the power conversion efficiencies.[30, 31] Moreover, in past decade, piezoelectric polarizations have been proposed and ulitized by Wang et al in piezoelectric semiconducting materials (e.g. $\mathrm{ZnO}$, $\mathrm{GaN}$ and $\mathrm{CdS}$ nanowires) to regulate charge seperation and collection, tune transport barrier height and adjust depletions regions in many electronic, photonic and optoelectric systems.[32-41] In addition to the piezotronic effect which describes the regulation of piezoelectric polarizations on the electrical transport properties, the recent piezo-phototronic effect has been suggested and proved to be able to effectively enhance/regulate the performance of photovoltaic device,[32-35] optoelectronic light-emitting diodes,[36, 37] photodectors, [38, 39] and photocatalysis.[40, 41] Given the fact that $\mathrm{CH}_{3} \mathrm{NH}_{3} \mathrm{PbI}_{3}$ has been projected to be ferroelectric material, it is natural to consider that the polarization-induced electric field should play an important role in regulating the performance of perovskite solar cells. The hysteretic behavior of $J-V$ characteristics observed under different scanning directions and scanning rates has been recently reported.[42-46] The origin of hysteretic behaviors is not very clear. It is speculated to be related with ferroelectric polarization[42, 43] and other reasons, such as capacitive charge,[44, 45] photo-induced ion migration,[42] trapping/de-trapping of charge carries,[46] and changes of permittivity.[43] The relation of $J$ $V$ hysteretic behavior with ferroelectric domains is one of the foci in this study.

Here, we demonstrate the ferroelectric effect of $\mathrm{CH}_{3} \mathrm{NH}_{3} \mathrm{PbI}_{3}$ using piezoresponse force microscopy (PFM) and illustrate the effect of positive and negative poling on the performance of hybrid perovskite solar cells. Power conversion efficiencies are found to be significantly different for organometal halide perovskite solar cells under different poling electric field directions. The relationship of ferroelectric polarization and $J-V$ hysteretic behavior in both hybrid halide perovskite solar cell and oxide ferroelectric photovoltaic cell is revealed. Our finding opens an avenue to utilize the ferroelectric polarization in organometal halide perovskite material for designing and optimizing future reliably high-performance solar cells.

\section{Experimental Section}

Synthesis of $\mathrm{CH}_{3} \mathrm{NH}_{3} \mathbf{I}$ : Methylamine $(27.86 \mathrm{ml}, 40 \%$ in methanol, TCI) and hydroiodic acid (30 ml, $57 \mathrm{wt} \%$ in water, Sigma-Aldrich) were mixed at $0{ }^{\circ} \mathrm{C}$ and stirred for $2 \mathrm{~h}$. The precipitate was recovered by evaporation at $50{ }^{\circ} \mathrm{C}$ for $1 \mathrm{~h}$. The product was washed with diethyl ether three times and finally dried at $60{ }^{\circ} \mathrm{C}$ in a vacuum oven for $24 \mathrm{~h}$.

Organometal Halide Perovskite Solar Cells Fabrication: Fluorine-doped tin oxide (FTO) coated glasses $(7 \Omega / \mathrm{sq}$, Sigma-Aldrich) used in this study were ultrasonically cleaned with acetone, ethanol and deionized water, and then dried with a nitrogen stream. $60 \mathrm{~nm}$ compact $\mathrm{TiO}_{2}$ blocking layer was spin-coated on the FTO substrate at 2,000 rpm for $20 \mathrm{~s}$ using a mildly acidic titanium isopropoxide solution and heated at $200{ }^{\circ} \mathrm{C}$ for $5 \mathrm{~min}$. The compact $\mathrm{TiO}_{2}$ layer solution was prepared by adding $369 \mu \mathrm{L}$ of titanium isopropoxide $(99.99 \%$ SigmaAldrich) into $2.53 \mathrm{~mL}$ of ethanol. At the same time, $35 \mu \mathrm{L}$ of a $2 \mathrm{M} \mathrm{HCl}$ solution were added into $2.53 \mathrm{~mL}$ of ethanol in another vial. The second solution was then added dropwise to the first solution under stirring for $1 \mathrm{~h}$, and the mixture filtered with a PFTE $0.2 \mu \mathrm{m}$ filter. After cooling to room temperature, the $\mathrm{TiO}_{2}$ paste (Dyesol 18NR-T, Dyesol), diluted in terpineol 
and ethanol $\left(\mathrm{TiO}_{2}\right.$ : terpineol: ethanol= 1:3:3.5 wt $\left.\%\right)$ was spin-coated on the compact $\mathrm{TiO}_{2}$ layer at $6,000 \mathrm{rpm}$ for $60 \mathrm{~s}$. After drying at $120{ }^{\circ} \mathrm{C}$, the $\mathrm{TiO}_{2}$ films were sintered at $500{ }^{\circ} \mathrm{C}$ for 15 min and cooled to $80{ }^{\circ} \mathrm{C}$. $250 \mathrm{~nm} \mathrm{CH} \mathrm{CH}_{3} \mathrm{NH}_{3} \mathrm{PbI}_{3}$ was fabricated using two-step spin-coating procedure similar to that reported in ref $3 . \mathrm{PbI}_{2}$ was dissolved in $\mathrm{N}, \mathrm{N}$-dimethylformamide and stirring at room temperature overnight. The mesoporous $\mathrm{TiO}_{2}$ films $(260 \mathrm{~nm})$ were then infiltrated with $\mathrm{PbI}_{2}$ by spin coating at $1000 \mathrm{rpm}$ for $10 \mathrm{~s}$ and $4000 \mathrm{rpm}$ for $20 \mathrm{~s}$, and then dried at $70{ }^{\circ} \mathrm{C}$ for $30 \mathrm{~min}$. After cooling to room temperature, $100 \mu \mathrm{l}$ of $0.050 \mathrm{M}(8 \mathrm{mg} / \mathrm{ml})$ $\mathrm{CH}_{3} \mathrm{NH}_{3} \mathrm{I}$ solution in 2-propanol was loaded on the $\mathrm{PbI}_{2}$-coated substrate for $20 \mathrm{~s}$ (loading time), which was spun at $3,000 \mathrm{rpm}$ for $30 \mathrm{~s}$ and dried at $70{ }^{\circ} \mathrm{C}$ for $30 \mathrm{~min}$. The HTM layer with $300 \mathrm{~nm}$ thickness was then deposited by spin coating at 3,000 rpm for $30 \mathrm{~s}$. The HTM solution was prepared by dissolving $90 \mathrm{mg}$ spiro-MeOTAD [2,2',7,7'-tetrakis(N,N-di-pmethoxyphenylamine)-9,9-spirobifluorene] in $1 \mathrm{ml}$ chlorobenzene, with addition of $45 \mu \mathrm{L} \mathrm{Li}$ TFSI/acetonitrile $(170 \mathrm{mg} / \mathrm{mL})$, and $75 \mu \mathrm{L}$ [tris(2-(1H-pyrazol-1-yl)-4-tertbutylpyridine)cobalt(III) bis(trifluoromethylsulphonyl) imide] (FK209) /acetonitrile (100 $\mathrm{mg} / \mathrm{mL}$ ) and $10 \mu \mathrm{L}$ 4-tert-butylpyridine (TBP). Finally, $100 \mathrm{~nm}$ of gold was thermally evaporated on the spiro-MeOTAD-coated film. The active area of each device was $0.1 \mathrm{~cm}^{2}$.

Ferroelectric Solar Cells Fabrication: The target of $(1-\mathrm{x}) \mathrm{BaTiO}_{3}-\mathrm{xBiFeO}_{3}(\mathrm{x}=0.725)$ (BT-BFO) was synthesized using the solid state reaction method. For this, stoichiometric amounts of $\mathrm{TiO}_{2}, \mathrm{Bi}_{2} \mathrm{O}_{3}, \mathrm{Fe}_{2} \mathrm{O}_{3}, \mathrm{BaCO}_{3}$ from (Ward Hill, USA) were ball milled under ethanol for $24 \mathrm{~h}$ followed by drying at $80{ }^{\circ} \mathrm{C}$ for $6 \mathrm{~h}$. The obtained powder was calcined at $1000{ }^{\circ} \mathrm{C}$ for $2 \mathrm{~h}$ followed by ball milling for $48 \mathrm{~h}$ under ethanol. Then the powder was pressed in to a cylindrical target using uniaxial pressing followed by isostatic pressing (CIP) to achieve high green density. The cylindrical target was sintered at $1350{ }^{\circ} \mathrm{C}$ for $2 \mathrm{~h}$ to achieve highly dense (>95.5\%) body. $\mathrm{Nb}-(0.7 \mathrm{wt} \%)$ doped $\mathrm{SrTiO}_{3}$ was used as a substrate and it was degreased by acetone and 2-propanol, and finally rinsing in deionized water for $1 \mathrm{~min} .50 \mathrm{~nm}$ BT-BFO thin-films were deposited by pulsed laser deposition (PLD) technique using a $\mathrm{KrF}$ excimer laser $(\lambda=248 \mathrm{~nm})$ on $\mathrm{Nb}: \mathrm{SrTiO}_{3}$ at a deposition rate of $0.5 \AA / \mathrm{s}$ using the synthesized BT-BFO target. The focused laser beam irradiates the rotating target at $89 \mathrm{rpm}$ with a laser energy density of $\sim 2.5 \mathrm{~J} / \mathrm{cm}^{2}$ at a repetition rate of $10 \mathrm{~Hz}$ in an oxygen pressure of $300 \mathrm{mTorr}$ and the temperature was maintained at $800{ }^{\circ} \mathrm{C}$ during the deposition. The thickness of BTBFO film was $50 \mathrm{~nm} .20 \mathrm{~nm}$ Pt top electrodes were deposited through shadow mask using magnetic sputtering technique.

Characterization: Piezoelectric force microscopy (PFM) was performed using a scanning probe station (Bruker Dimension Icon, USA) with conductive Platinum-Iridium coated tip (SCM-PIT, Bruker). All the piezoresponse phase mappings were conducted under resonanceenhanced mode. In order to investigate the polarization switching behavior of domains, either a positive or negative DC bias was applied using the scanning tip on the specimen. For local hysteresis loop measurement, the out-of-plane piezoresponse was measured at selected locations on the ferroelectric film surface as a function of DC bias superimposed on the AC modulation bias. The AC drive amplitude was $1000 \mathrm{mV}(\sim 300 \mathrm{kHz})$ during the $\mathrm{DC}$ bias sweep. Photovoltaic performance of the solar cells were analyzed under one sun AM 1.5 (100 $\left.\mathrm{mW} / \mathrm{cm}^{2}\right)$ illumination with a solar simulator $\left(150 \mathrm{~W} \mathrm{Sol} 2 \mathrm{~A}^{\mathrm{TM}}\right.$, Oriel $)$. The power output of the lamp was calibrated to 1 Sun (AM1.5G, $100 \mathrm{~mW} \mathrm{cm-2)} \mathrm{using} \mathrm{a} \mathrm{certified} \mathrm{Si} \mathrm{reference} \mathrm{cell.}$ During the measurement, different bias voltages were applied on the solar cell for $10 \mathrm{~s}$ to pole the perovskite thin layer, and then solar cells were short circuited for $5 \mathrm{~s}$ after poling to avoid the effect of capacitive charging during the poling, subsequently, the current-voltage characteristics of each cell were recorded with a Keithley digital source meter (model 2400). During electric poling, the applied voltage is applied on the top Au electrode for $\mathrm{CH}_{3} \mathrm{NH}_{3} \mathrm{PbI}_{3}$ solar cells and on the top Pt electrode for BT-BFO solar cells. Scanning electron microscopy images were obtained from scanning electron microscopy (SEM, Quanta 600 FEG, FEI Company) operated at an accelerating voltage of $5 \mathrm{kV}$. 


\section{Results and Discussion}

Ferroelectric properties of $\mathrm{CH}_{3} \mathrm{NH}_{3} \mathrm{PbI}_{3}$ perovskite layer were investigated by PFM. PFM phase contrast image in Figure 1 demonstrates the change of polarization in the as-grown $\mathrm{CH}_{3} \mathrm{NH}_{3} \mathrm{PbI}_{3}$ thin film under different applied bias voltage. After electric poling by $-3 \mathrm{~V}$ DC bias, the contrast in the phase image appears with a peak distribution of phase angle located at $-90^{\circ}$ (Figure $1 \mathrm{~b}$ and 1f). This significant out-of-plane component of polarization indicates the alignment of dipoles in $\mathrm{CH}_{3} \mathrm{NH}_{3} \mathrm{PbI}_{3}$ under applied electric field. Subsequently, the same sample was poled with $+3 \mathrm{~V}$ DC bias (Figure 1c). An obviously shift of phase angle distribution can be noticed as compared to that of $-3 \mathrm{~V}$ poled sample (Figure 1b), indicating an effective domain switching under the external positive electric bias. Following the poling action in Figure 1c, the bottom half part of the scanning area was further poled with $-3 \mathrm{~V}$. In Figure 1d, we can clearly observe the variation of phase contrast in the bottom regime, whereas the top regime remains same. Figure 1e illustrates the variation of phase angle distribution between the unpoled and half-poled samples. In addition, we investigated the effective local piezoresponse using resonance enhanced ramp mode as shown in Figure $1 \mathrm{~g}$ and $h$. Quantitative variation of the phase angle and phase amplitude reflects the magnitude of the deformation under external DC bias sweep. Piezoresponse phase and amplitude demonstrate a hysteretic response with $180^{\circ}$ phase switching for $\mathrm{CH}_{3} \mathrm{NH}_{3} \mathrm{PbI}_{3}$ perovskite films (Figure $1 \mathrm{~g}$ and $\mathrm{h}$ ). Considering the thickness of the film was $250 \mathrm{~nm}$, the polarization switching at $-0.2 \mathrm{~V}$ and $+0.2 \mathrm{~V}$ indicates the coercive field for $\mathrm{CH}_{3} \mathrm{NH}_{3} \mathrm{PbI}_{3}$ perovskite is only $8 \mathrm{kV} / \mathrm{cm}$, which is much lower than the other reported inorganic ferroelectric thin films.[20, 47] Therefore, Figure 1 demonstrates that the $\mathrm{CH}_{3} \mathrm{NH}_{3} \mathrm{PbI}_{3}$ perovskite film has promising ferroelectric properties with switchable domains and polarization hysteresis.

The influence of ferroelectric $\mathrm{CH}_{3} \mathrm{NH}_{3} \mathrm{PbI}_{3}$ polarization on the performance of organometal halide perovskite solar cells was explored by varying the polarization states. The corresponding $J-V$ characteristics were shown in Figure 2, and the photovoltaic parameters are summarized in Table 1. Figure 2 a shows the poling effect on the perovskite solar cells with mesoporous- $\mathrm{TiO}_{2}\left(\mathrm{mp}-\mathrm{TiO}_{2}\right)$ ETL and spiro-MeOTAD HTM layer. Though positive poling does not render obvious changes on the $J-V$ characteristics, the negative poling significantly reduces the photovoltaic efficiency; $V_{O C}$ was decreased from $1.00 \mathrm{~V}$ to $0.90 \mathrm{~V}$, $J_{S C}$ was reduced from $20.06 \mathrm{~mA} / \mathrm{cm}^{2}$ to $17.13 \mathrm{~mA} / \mathrm{cm}^{2}$, fill factor $(F F)$ was decreased from $64.53 \%$ to $55.92 \%$, and $\eta$ was decreased from $13.01 \%$ to $8.64 \%$. If the cells were further applied positve poling after the negative poling, the photovoltaic performance can be recovered as shown in Figure S1. In our experiment, in order to avoid the effect of capacitive charging along with the poling, before the $J-V$ test, the solar cells were short circuited for $5 \mathrm{~s}$ after poling. For planar perovskite solar cells with compact $\mathrm{TiO}_{2}\left(\mathrm{cp}-\mathrm{TiO}_{2}\right)$ blocking layer and $H T M$ (Figure 2c), the effects of positive poling and negative poling for $\mathrm{CH}_{3} \mathrm{NH}_{3} \mathrm{PbI}_{3}$ layer led to similar observations as the case of mesoporous- $\mathrm{TiO}_{2}$ based perovskite solar cells. In order to acquire a comprehensive understanding of the ferroelectric function of $\mathrm{CH}_{3} \mathrm{NH}_{3} \mathrm{PbI}_{3}$, we further studied the HTM-free planar perovskitesolar cells to avoid the influence of spiroMeOTAD and mesoporous- $\mathrm{TiO}_{2}$. Due to the absence of $\mathrm{CH}_{3} \mathrm{NH}_{3} \mathrm{PbI}_{3} /$ mesoporous- $\mathrm{TiO}_{2}$ and $\mathrm{CH}_{3} \mathrm{NH}_{3} \mathrm{PbI}_{3} / H T M$ interfaces, the separation of photo-generated charges were not efficient which led to very low $\eta$ for as-grown $H T M$-free planar perovskite solar cells (Figure 2e). Positive poling of ferroelectric $\mathrm{CH}_{3} \mathrm{NH}_{3} \mathrm{PbI}_{3}$ layer doubles $J_{S C}$ and enhances the $\eta$ by a factor of five, while negative poling greatly suppresses the photovoltaic performance (Table 1). These results in Figure2 indicate the polarization of the ferroelectric $\mathrm{CH}_{3} \mathrm{NH}_{3} \mathrm{PbI}_{3}$ layer plays a significant role on the separation and recombination of the photo-generated charges.

With the perovskite absorber identified with ferroelectric properties, the perovskite solar cells in our system can be modeled as a $p-F E-n$ structure, where $p$ denotes $H T M, n$ denotes 
ETL and FE denotes ferroelectric $\mathrm{CH}_{3} \mathrm{NH}_{3} \mathrm{PbI}_{3}$. The detailed band diagram of the isolated $\mathrm{TiO}_{2}, \mathrm{CH}_{3} \mathrm{NH}_{3} \mathrm{PbI}_{3}$ and spiro-MeOTAD with quantitative values on certain energy levels are shown in Figure S2a. Since the Fermi level of the perovskite layer is unknown, it is challenging to quantitatively draw the band diagrams of the contacted structure. Therefore here we illustrate the schematic of band diagram under intrinsic condition, positive poling and negative poling conditions in Figure 3. By assuming that the Fermi level of the perovskite layer is located in the middle of its band gap, in Figure S2 we also sketch the band alignment of the contacted structures with quantitative values on certain important energy levels. It shall be noted that such band alignment is based on an approximate assumption of the position of the perovskite's Fermi level and therefore it stays as a comparison to the case in Fig. 3. In both cases (Figure 3 and Figure S2) the conclusion remains consistent. Besides the intrinsic space charge-induced built-in electric field inside the $F E$ layer (in Figure $3, E_{b i}$ is a general term for the built-in electric field in FE layer, $E_{b i_{-}}$is the built-in electric field in $F E$ layer close to ETL side, $E_{b i \_}$is the built-in electric field in FE layer close to the HTM side; similarly, $W_{b i_{-} 1}$ and $W_{b i_{-} 2}$ represent their corresponding widths of depletion regions in $F E$ layer, respectively), we reveal that the ferroelectric polarization of $\mathrm{CH}_{3} \mathrm{NH}_{3} \mathrm{PbI}_{3}$ evokes polarization electric field (in Figure $3, E_{p}$ represents ferroelectric polarization field, $W_{-} p$ is the width of depletion region solely due to the ferroelectric polarization in the $F E$ layer close to $n$ side, $W_{-} p 2$ is the width of depletion region solely due to the ferroelectric polarization in the $F E$ layer close to $H T M$ side, $\boldsymbol{P}$ denotes the ferroelectric polarization) as another driving force for charge separation/recombination.

Interface band structure engineering by ferroelectric polarization is proposed here to understand photovoltaic performance. In the absence of a ferroelectric polarization, the energy band diagram can be modelled as a $p-i-n$ structure shown in Figure 3a. It should be noted that due to the semiconductor property of the absorber layer we leave a flat band in the "i" layer with two depletion regions $\left(W_{b i_{-} l}\right.$ and $\left.W_{b i_{2}}\right)$ at $n / F E$ and $F E / p$ interfaces.[48] This has been revealed by electron beam-induced current (EBIC) experiment recently.[12, 13]

Under negative poling, the dipoles of ferroelectric $\mathrm{CH}_{3} \mathrm{NH}_{3} \mathrm{PbI}_{3}$ are aligned with positive ferroelectric charges located at $p-F E$ interface and an equal quantity of negative ferroelectric charges at $F E$ - $n$ interface. Polarization is marked by the $\boldsymbol{P}$ vector shown in Figure $3 \mathrm{~b}$. With such ferroelectric polarization, i.e. negative charges at $n-F E$ interface and positive charges at $F E$ - $p$ interface, the depletion regions in the $F E$ layer at both sides would become narrower. The updated widths of depletion regions become $\left(W_{b i_{-} l}-W_{-p l}\right)$ and $\left(W_{b i_{-} l}-W_{-} p\right)$, respectively (Figure $3 \mathrm{~b}$ ). As a result, under negative poling, the driving forces either to extract electrons to $E T L$ or to push holes to $H T M$ become smaller. Overall, $E_{p}$ counters the drift of electron and hole and suppresses the overall $J_{S C}$, as demonstrated in Figure 2. Based on general solar cell physics, $J_{S C}$ determines $V_{O C}$ through the expression:

$$
V_{o c}=\frac{n k T}{e} \ln \left(\frac{J_{S C}}{J_{0}}+1\right)
$$

where $k$ is the Boltzmann constant, $T$ is the absolute temperature, $e$ is the charge of an electron, $n$ is the ideality factor, and $J_{0}$ is the reverse saturation current. Considering that the reverse saturation current does not have appreciable change after the electric poling (Figure S3), the reduced $J_{S C}$ is likely the reason for the reduction of $V_{O C}$ value under negative poling. Because the coercive voltage is $0.2 \mathrm{~V}$ for $\mathrm{CH}_{3} \mathrm{NH}_{3} \mathrm{PbI}_{3}$ thin film, the polarization electric field is not large enough to switch the direction of the built-in electric field, thus the direction of photocurrent and photo-voltage cannot be switched.

Positive poling renders the positive ferroelectric charges in $\mathrm{CH}_{3} \mathrm{NH}_{3} \mathrm{PbI}_{3}$ at the $n-F E$ interface and negative ferroelectric charges at the $F E-p$ interface, which leads to $E_{p}$ in the same direction as $E_{b i}$. This enables the expansion of depletion regions in the $F E$ layer on both sides. The updated widths of depletion regions become $\left(W_{b i_{-} l}+W_{-p 1}\right)$ and $\left(W_{b i_{-} l}+W_{-} 1\right)$, 
respectively (Figure 3c). Accordingly, we expected to see an increase of the photovoltaic performance with positive poling. However, as shown in Figure 2a and c, the positive poling does not demonstrate significant changes of the photovoltaic performance when HTM and ETL are both used. Such phenomenon initially was a puzzle to us until a control experiment was executed in Figure 2e. For HTM-free perovskite solar cells, the band structure is more like a $n$-FE-electrode system. Here, charge separation is mainly responsible by the $F E$ component, and the performance of $F E$ layer is a rate-limiting factor to extract holes out. In Figure 2e, the un-poled sample shows very poor performance featured by its extremely low fill factor indicating a very sloppy charge separation. After positive poling, the photovoltaic performance is dramatically improved with an increase of efficiency by $500 \%$ ! With negative poling, a significant decrease of photovoltaic performance is observed. These two observations align properly with our model explained in Figure 3.

However, in the $n-F E-p$ system, EBIC experiment has clearly shown that the rate-limiting factor is $H T M$ layer rather than $F E$ itself when $F E$ layer is not polarized.[12, 13] Now, though positive polarization leads to the boosting of the driving force inside $F E$ layer, we should not expect an appreciable increase (a slight increase indeed was observed, as shown in Figure 2a and c) of photovoltaic performance since $H T M$ is the bottleneck under this scenario. When $F E$ layer is negatively polarized, the driving force inside $F E$ layer becomes substantially reduced. Based on our observations in Figure $2 \mathrm{a}$ and $\mathrm{c}$, this apparently makes the rate-limiting component switched from $H T M$ to $F E$ since the photovoltaic performance becomes deteriorated. Further in another control experiment as shown in Figure S4, when the efficiency for planar perovskite solar cells with $H T M$ is low due to inefficient charge separation as a result of the poor-quality perovskite itself (now perovskite $F E$ layer serves as a rate-limiting component), positive poling boosts the photovoltaic performance by a great proportion. In other words, when $F E$ itself becomes the dominant factor, any change inside $F E$ translates into the photovoltaic performance.

Figure 4a shows the effect of poling field magnitude on mp- $\mathrm{TiO}_{2}$ based $\mathrm{CH}_{3} \mathrm{NH}_{3} \mathrm{PbI}_{3}$ solar cells. When the applied negative poling voltage is reduced from $-0.5 \mathrm{~V}$ to $-1.5 \mathrm{~V}$, and further to $-3 \mathrm{~V}$, both $V_{O C}$ and $J_{S C}$ were gradually decreased. Consequently, the efficiencies of $\mathrm{CH}_{3} \mathrm{NH}_{3} \mathrm{PbI}_{3}$ solar cells kept reducing with the increase of negative poling electric field (Table S2). If positive poling is further applied to the negatively poled samples, the efficiency can be completely recovered. When the negative poling electric field is small, the dipoles in ferroelectric $\mathrm{CH}_{3} \mathrm{NH}_{3} \mathrm{PbI}_{3}$ may not be completely switched resulting in inhomogeneous polarization distribution. Increase of the negative poling electric field can further align the dipoles and create larger $E_{p}$ to hinder charge separation. This explains why the efficiencies of solar cells can be further reduced with increase of negative poling field magnitude in Figure $3 a$.

The relation of ferroelectric effect with hysteretic behavior in the $J$ - $V$ measurement is investigated in Figure $4 \mathrm{~b}$. The $\mathrm{CH}_{3} \mathrm{NH}_{3} \mathrm{PbI}_{3}$ solar cells exhibit lower photovoltaic performance under forward scan than that under reverse scan. Upon increasing the initial bias voltage of forward scans from $-0.5 \mathrm{~V}$ to $-3 \mathrm{~V}$, the $J-V$ curves kept moving downwards. Interestingly, linear forward scan from $-0.5 \mathrm{~V}$ to $1.1 \mathrm{~V}$ has similar performance as forward scan from $-0.1 \mathrm{~V}$ to $1.1 \mathrm{~V}$ after $-0.5 \mathrm{~V}$ poling. Similarly, large forward scan region from $-3 \mathrm{~V}$ to $1.1 \mathrm{~V}$ shows almost same efficiency as forward scan $(-0.1 \mathrm{~V}$ to $1.1 \mathrm{~V})$ after poling at $-3 \mathrm{~V}$. Moreover, the $J-V$ curve of reverse scan from $1.1 \mathrm{~V}$ to $-0.1 \mathrm{~V}$ after $+2 \mathrm{~V}$ poling overlaps with the linear reverse scan from $2 \mathrm{~V}$ to $-0.1 \mathrm{~V}$. This indicates that the polarization switching of ferroelectric $\mathrm{CH}_{3} \mathrm{NH}_{3} \mathrm{PbI}_{3}$ has remarkable implication on the $J-V$ hysteretic behavior and the efficiency of perovskite solar cells.

Considering domains of $\mathrm{CH}_{3} \mathrm{NH}_{3} \mathrm{PbI}_{3}$ thin film can be switched at $-0.2 \mathrm{~V}$ and $+0.2 \mathrm{~V}$ bias voltage due to the low coercive field, the ferroelectric polarization can be changed even during typical solar cell characterization process. The polarization switching of ferroelectric 
$\mathrm{CH}_{3} \mathrm{NH}_{3} \mathrm{PbI}_{3}$ polarization during solar cell characterization process plays an important role on the $J$ - $V$ hysteretic behavior. For the forward scan, ferroelectric $\mathrm{CH}_{3} \mathrm{NH}_{3} \mathrm{PbI}_{3}$ domains are initially negative poled, which decreases the driving force for charge separation and reduces the photovoltaic efficiency. The lower the initial forward scan voltage (more negative voltage, such as $-3 \mathrm{~V}$ ), the larger is the $E_{p}$. The negative poling's impact at $-3 \mathrm{~V}$ poling is close to a linear forward scan from $-3 \mathrm{~V}$ to $1.1 \mathrm{~V}$. Similarly, the reverse scan first activates the positive poling to increase the net electric field and ensures the high efficiency. All the data indicates that $J-V$ hysteretic behavior of hybrid perovskite solar cells is closely related to the ferroelectric properties. However, the capacitive characteristic, $[44,45]$ photo-induced charge migration, [42] and other factors may play synergistic effects with ferroelectric effect to $J$ - $V$ hysteretic behavior.

Similar evidence of the effect of ferroelectric polarization on the performance of traditional ferroelectric solar cells and their $J-V$ hysteresis was also observed. In the control experiments, we fabricated the $\mathrm{Nb}-\mathrm{SrTiO}_{3} / \mathrm{BaTiO}_{3}-\mathrm{BiFeO}_{3} / \mathrm{Pt}$ ferroelectric solar cells by depositing $50 \mathrm{~nm}$ $\mathrm{BaTiO}_{3}-\mathrm{BiFeO}_{3}$ (BT-BFO) on the conductive $\mathrm{Nb}-\mathrm{SrTiO}_{3}$ substrate. Semitransparent Pt thin film with $20 \mathrm{~nm}$ thickness (as shown in Figure S5 and S6) was utilized as top electrode.[4951] Figure 5a and $b$ demonstrate the ferroelectric domain and polarization hysteresis for BTBFO thin film. As shown in Figure 5c, positive poling increases the efficiency of the BT-BFO solar cells, while negative poling reduces the efficiency. With the increase of positive poling voltage, the efficiencies of ferroelectric solar cells keep decreasing. Forward and reverse scans between $-1.5 \mathrm{~V}$ to $+1.5 \mathrm{~V}$ for BT-BFO solar cells also demonstrate $J$ - $V$ hysteretic behavior (Figure $5 \mathrm{~d}$ ). Moreover, reverse scan from $0.8 \mathrm{~V}$ to $-0.1 \mathrm{~V}$ after $+1.5 \mathrm{~V}$ poling shows similar efficiency as linear reverse scan from $1.5 \mathrm{~V}$ to $-1.5 \mathrm{~V}$; similarly, scan from $0.8 \mathrm{~V}$ to $0.1 \mathrm{~V}$ after $-1.5 \mathrm{~V}$ poling has similar performance as forward scan from $-1.5 \mathrm{~V}$ to $1.5 \mathrm{~V}$.

The detailed band diagram of the isolated $\mathrm{Nb}-\mathrm{SrTiO}_{3}, \mathrm{BT}-\mathrm{BFO}$, Pt and the corresponding heterojunction at thermal equilibrium condition are shown in Figure S7a and $b$. Under the positive poling for $\mathrm{Nb}-\mathrm{SrTiO}_{3} / \mathrm{BT}-\mathrm{BFO} / \mathrm{Pt}$ solar cells, the ferroelectric field is in the same direction as built-in electric field (Figure S7c), therefore, the band bending increases with larger net built-in electric field and driving potential. In this case, we expect an increase of the photovoltaic performance under positive poling, which, however, contradicts with the experimental finding. This might be due to the ferroelectricity-induced resistive switching for the BTBFO thin films under different FE's polarizations. [52, 53] We found the BT-BFO thin films showing large reverse saturation current $\left(J_{0}\right)$ with low resistance state (LRS) under positive poling, while demonstrated small $J_{0}$ with high resistance state (HRS) under negative poling (Figure S8). Moreover, due to the large band gap of BT-BFO $(3.0 \mathrm{eV})$, there is only a small quantity of photo-generated charges in BT-BFO solar cells. The net electric field can efficiently separate charges under both positive and negative poling, which leads to same $J_{S C}$ value under different poling conditions. According to equation 1, large $J_{0}$ with LRS under positive poling leads to small $V_{O C}$, and small $J_{O}$ with HRS under negative poling increases the $V_{O C}$ for BT-BFO ferroelectric solar cells. As we can notice, the negative poling in ferroelectric solar cells enhances the photovoltaic efficiency, while negative poling in $\mathrm{CH}_{3} \mathrm{NH}_{3} \mathrm{PbI}_{3}$ solar cells reduces the efficiency. The difference comes from their distinct detailed architectures and materials components. Nevertheless, it is the ferroelectric polarization playing a substantial role on both types of cells' $J$ - $V$ hysteresis. These results in Figure 5 confirm the similar impact of electric poling and scan directions on the photovoltaic performance for BT-BFO ferroelectric solar cells as $\mathrm{CH}_{3} \mathrm{NH}_{3} \mathrm{PbI}_{3}$ solar cells.

\section{Conclusion}

In summary, we have demonstrated the ferroelectric nature of $\mathrm{CH}_{3} \mathrm{NH}_{3} \mathrm{PbI}_{3}$ and further identified the role of its ferroelectric polarization on the performance of organometal halide 
perovskite solar cell. Ferroelectric polarization of $\mathrm{CH}_{3} \mathrm{NH}_{3} \mathrm{PbI}_{3}$ can regulate the interface band structure of perovskite solar cells. Negative poling yields a countering ferroelectric polarization field that reduces the driving force for charge separation, therefore, a significantly reduced photovoltaic efficiency is observed. Positive poling can align the domain polarization in a preferable direction and increases the net electric field and expands the width of depletion region, which is found to assist the charge separation at certain scenarios. The low coercive field of $\mathrm{CH}_{3} \mathrm{NH}_{3} \mathrm{PbI}_{3}$ leads to easy ferroelectric polarization switching. During solar cell characterization, the forward scan of $J-V$ curve leads to low power conversion efficiency due to the negatively poled domains and the reverse scan leads to higher efficiency due to the positive poled domains. In the control experiment, the electric poling and scan direction also shows a significant impact on the photovoltaic performance of the BT-BFO ferroelectric solar cells indicating the universality and generality of this behavior in ferroelectric material-based solar cells. The ferroelectric polarization provides a new perspective for tailoring the working mechanism and photovoltaic performance of the perovskite solar cells.

\section{Acknowledgements}

The authors gratefully acknowledge the financial support through US Army under contract No. W15P7T-13-C-A910. The work at the National Renewable Energy Laboratory was supported by the U.S. Department of Energy under Contract No. DE-AC36-08-GO28308. K.Z. and M.Y. acknowledge the support by the U.S. Department of Energy (DOE) SunShot Initiative under the Next Generation Photovoltaics 3 program (DE-FOA-0000990).

\section{References:}

[1] G. Xing, N. Mathews, S. Sun, S.S. Lim, Y.M. Lam, M. Gräetzel, S. Mhaisalkar, T.C. Sum, Science, 342 (2013) 344-347.

[2] J. Burschka, N. Pellet, S.J. Moon, R. Humphry-Baker, P. Gao, M.K. Nazeeruddin, M. Grätzel, Nature, 499 (2013) 316-319.

[3] J.H. Im, I.H. Jang, N. Pellet, M. Gräetzel, N.G. Park, Nat. Nanotechnol., 9 (2014) 927-932. [4] D. Zhong, B. Cai, X.L. Wang, Z. Yang, Y.D. Xing, S. Miao, W.H. Zhang, C. Li, Nano Energy, 11 (2015) 409-418.

[5] Y.X. Zhao, K. Zhu, J. Am. Chem. Soc., 136 (2014) 12241-12244.

[6] D. Liu, T.L. Kelly, Nature Photonics, 8 (2013) 133-138.

[7] B. Cai, Y. Xing, Z. Yang, W.-H. Zhang, J. Qiu, Energy Environ. Sci., 6 (2013) 1480-1485. [8] A. Mei, X. Li, L. Liu, Z. Ku, T. Liu, Y. Rong, M. Xu, M. Hu, J. Chen, Y. Yang, M. Grätzel, H.W. Han, Science, 345 (2014) 295-298.

[9] H. Choi, J. Jeong, H.B. Kim, S. Kim, B. Walker, G.H. Kim, J.Y. Kim, Nano Energy, 7 (2014) 80-85.

[10] H.P. Zhou, Q. Chen, G. Li, S. Luo, T.B. Song, H.S. Duan, Z.R. Hong, J.B. You, Y.S. Liu, Y. Yang, Science, 345 (2014) 542-546.

[11] http://www.nrel.gov/ncpv/images/efficiency_chart.jpg, accessed 24 November 2014.

[12] E. Edri, S. Kirmayer, S. Mukhopadhyay, K. Gartsman, G. Hodes, D. Cahen, Nat. Commun., 5 (2014) 3461.

[13] M.A. Green, A. Ho-Baillie, H.J. Snaith, Nat. Photonics, 8 (2014) 506-514. 
[14] J. Seo, S. Park, Y.C. Kim, N.J. Jeon, J.H. Noh, S.C. Yoon, S.I. Sang, Energy Environ. Sci., 7 (2014) 2642-2646.

[15] P. Docampo, F.C. Hanusch, S.D. Stranks, M. Doeblinger, J.M. Feckl, M. Ehrensperger, N.K. Minar, M.B. Johnston, H.J. Snaith, T. Bein, Adv. Energy Mater., 4 (2014) 1400355.

[16] T. Baikie, Y. Fang, J.M. Kadro, M. Schreyer, F. Wei, S.G. Mhaisalkar, M. Grätzel, T.J. White, J. Mater. Chem. A, 1 (2013) 5628.

[17] Y. Kutes, L.H. Ye, Y.Y. Zhou, S.P. Pang, B.D. Huey, N.P. Padture, J. Phys. Chem. Lett., (2014) 3335-3339.

[18] C.C. Stoumpos, C.D. Malliakas, M.G. Kanatzidis, Inorg. Chem., 52 (2013) 9019-9038.

[19] J.M. Frost, K.T. Butler, F. Brivio, C.H. Hendon, M. van Schilfgaarde, A. Walsh, Nano Lett., 14 (2014) 2584-2590.

[20] T. Choi, S. Lee, Y.J. Choi, V. Kiryukhin, S.W. Cheong, Science, 324 (2009) 63-66.

[21] I. Grinberg, D.V. West, M. Torres, G. Gou, D.M. Stein, L. Wu, G. Chen, E.M. Gallo, A.R. Akbashev, P.K. Davies, J.E. Spanier, A.M. Rappe, Nature, 503 (2013) 509-512.

[22] F. Zheng, Y. Xin, W. Huang, J. Zhang, X. Wang, M. Shen, W. Dong, L. Fang, Y. Bai, X. Shen, J. Hao, J. Mater. Chem. A, 2 (2014) 1363.

[23] R. Nechache, C. Harnagea, S. Li, L. Cardenas, W. Huang, J. Chakrabartty, F. Rosei, Nat. Photonics, 9 (2015) 61-67.

[24] R. Moubah, O. Rousseau, D. Colson, A. Artemenko, M. Maglione, M. Viret, Adv. Funct. Mater., 22 (2012) 4814-4818.

[25] D. Cao, C. Wang, F. Zheng, W. Dong, L. Fang, M. Shen, Nano Lett., 12 (2012) 28032809.

[26] M. Alexe, D. Hesse, Nat. Commun., 2 (2011) 256.

[27] S.Y. Yang, J. Seidel, S.J. Byrnes, P. Shafer, C.H. Yang, M.D. Rossell, P. Yu, Y.H. Chu, J.F. Scott, J.W. Ager, III, L.W. Martin, R. Ramesh, Nat. Nanotech., 5 (2010) 143-147.

[28] A. Zenkevich, Y. Matveyev, K. Maksimova, R. Gaynutdinov, A. Tolstikhina, V. Fridkin, Phys. Rev. B, 90 (2014).

[29] G. Zhang, H. Wu, G. Li, Q. Huang, C. Yang, F. Huang, F. Liao, J. Lin, Sci. Rep., 3 (2013) 1265.

[30] Y.B. Yuan, T.J. Reece, P. Sharma, S. Poddar, S. Ducharme, A. Gruverman, Y. Yang, J.S. Huang, Nat. Mater., 10 (2011) 296-302.

[31] K.S. Nalwa, J.A. Carr, R.C. Mahadevapuram, H.K. Kodali, S. Bose, Y.Q. Chen, J.W. Petrich, B. Ganapathysubramanian, S. Chaudhary, Energy Environ. Sci., 5 (2012) 7042-7049.

[32] Y. Zhang, Y. Yang, Z.L. Wang, Energy Environ. Sci., 5 (2012) 6850-6856.

[33] Y. Yang, W. Guo, Y. Zhang, Y. Ding, X. Wang, Z.L. Wang, Nano Lett., 11 (2011) 4812 4817.

[34] C. Pan, S. Niu, Y. Ding, L. Dong, R. Yu, Y. Liu, G. Zhu, Z.L. Wang, Nano Lett., 12 (2012) 3302-3307.

[35] J. Shi, P. Zhao, X.D. Wang, Adv. Mater., 25 (2013) 916-921.

[36] Q. Yang, W. Wang, S. Xu, Z.L. Wang, Nano Lett., 11 (2011) 4012-4017.

[37] C. Pan, L. Dong, G. Zhu, S. Niu, R. Yu, Q. Yang, Y. Liu, Z.L. Wang, Nat. Photonics, 7 (2013) 752-758.

[38] Q. Yang, X. Guo, W. Wang, Y. Zhang, S. Xu, D.H. Lien, Z.L. Wang, ACS Nano, 4 (2010) 6285-6291.

[39] L. Dong, S. Niu, C. Pan, R. Yu, Y. Zhang, Z.L. Wang, Adv. Mater., 24 (2012) 54705475.

[40] M.B. Starr, X.D. Wang, Sci. Rep., 3 (2013) 2160.

[41] M.B. Starr, J. Shi, X.D. Wang, Angew. Chem. Int. Ed., 51 (2012) 5962-5966.

[42] E.L. Unger, E.T. Hoke, C.D. Bailie, W.H. Nguyen, A.R. Bowring, T. Heumuller, M.G. Christoforo, M.D. McGehee, Energy Environ. Sci., 7 (2014) 3690-3698. 
[43] J. Wei, Y.C. Zhao, H. Li, G.B. Li, J.L. Pan, D.S. Xu, Q. Zhao, D.P. Yu, J. Phys. Chem. Lett., (2014) 3937-3945.

[44] H.S. Kim, N.G. Park, J. Phys. Chem. Lett., 5 (2014) 2927-2934.

[45] R.S. Sanchez, V. Gonzalez-Pedro, J.W. Lee, N.G. Park, Y.S. Kang, I. Mora-Sero, J. Bisquert, J. Phys. Chem. Lett., 5 (2014) 2357-2363.

[46] H.J. Snaith, A. Abate, J.M. Ball, G.E. Eperon, T. Leijtens, N.K. Noel, S.D. Stranks, J.T.W. Wang, K. Wojciechowski, W. Zhang, J. Phys. Chem. Lett., 5 (2014) 1511-1515.

[47] W. Ji, K. Yao, Y.C. Liang, Adv. Mater., 22 (2010) 1763-1766.

[48] X.H. Liu, Y. Wang, J.D. Burton, E.Y. Tsymbal, Phys. Rev. B, 88 (2013) 165139.

[49] Y. Zhou, L. Fang, L. You, P. Ren, L. Wang, J. Wang, Appl. Phys. Lett., 105 (2014) 252903.

[50] D. Cao, H. Zhang, L. Fang, W. Dong, F. Zheng, M. Shen, Appl. Phys. Lett., 97 (2010) 102104.

[51] F. Zheng, J. Xu, L. Fang, M. Shen, X. Wu, Appl. Phys. Lett., 93 (2008) 172101.

[52] S. Hong, T. Choi, J.H. Jeon, Y. Kim, H. Lee, H.Y. Joo, I. Hwang, J.S. Kim, S.O. Kang, S.V. Kalinin, B.H. Park, Adv. Mater., 25 (2013) 2339-2343.

[53] Z.Q. Hu, Q. Li, M.Y. Li, Q.W. Wang, Y.D. Zhu, X.L. Liu, X.Z. Zhao, Y. Liu, S.X. Dong, Appl. Phys. Lett., 102 (2013) 102901. 

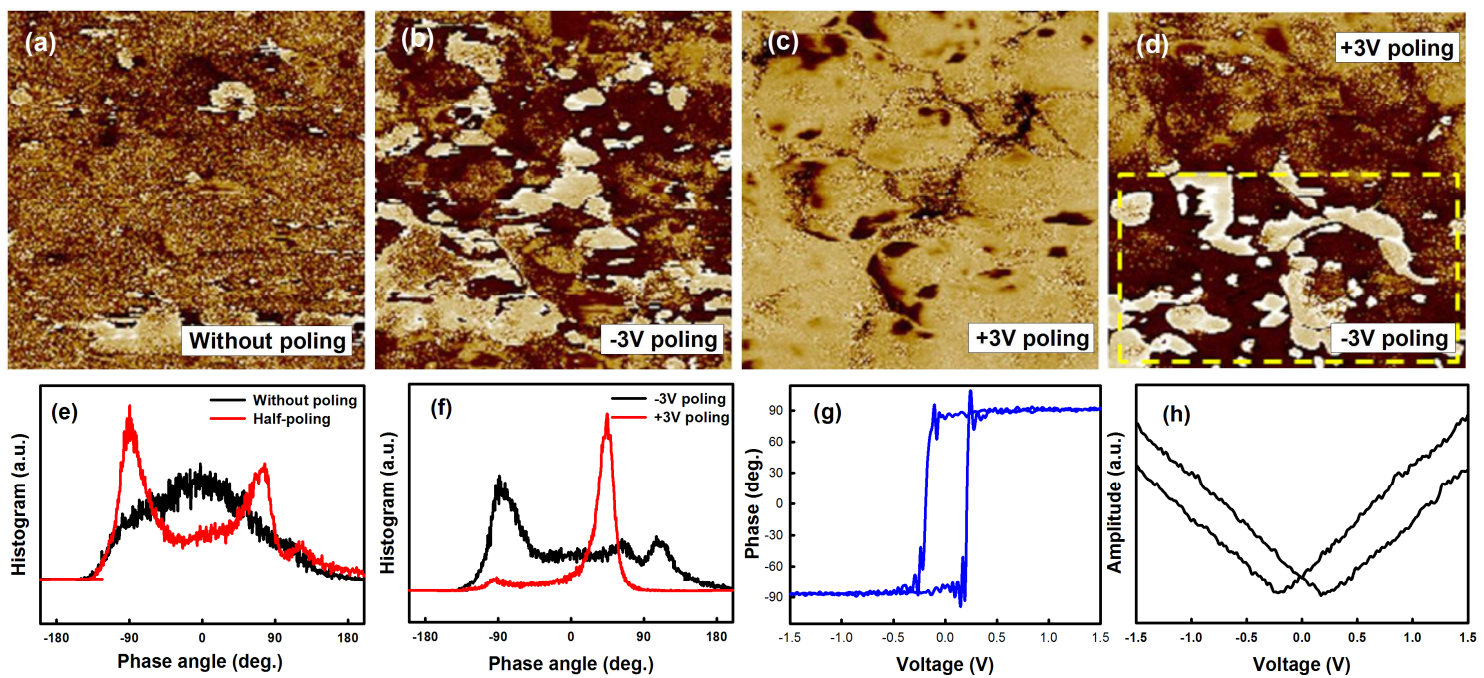

Figure 1. PFM phase image $(1.5 \mu \mathrm{m} \times 1.5 \mu \mathrm{m})$ for $250 \mathrm{~nm} \mathrm{CH}_{3} \mathrm{NH}_{3} \mathrm{PbI}_{3}$ thin film on FTO glass under different poling conditions: (a) without poling, (b) $-3 \mathrm{~V}$ poling, (c) $+3 \mathrm{~V}$ poling, and (d) top half region $+3 \mathrm{~V}$ poling and bottom half region $-3 \mathrm{~V}$ poling. (e) Domain phase angle distribution for (a) and (d). (f) Domain phase angle distribution for (b) and (c). (g) Piezoresponse phase and (h) piezoresponse amplitude at different bias voltages.


Figure $2 \mathrm{~J}-\mathrm{V}$ curves of three types of $\mathrm{CH}_{3} \mathrm{NH}_{3} \mathrm{PbI}_{3}$ (or $\mathrm{MAPbI}_{3}$ ) solar cells: (a) perovskite solar cells with mesoporous $\mathrm{TiO}_{2}$ scaffold, (c) planar perovskite solar cells, and (e) HTM-free planar perovskite solar cells, poled at different bias voltage. (b), (d), and (f) is corresponding SEM images for (a), (c), and (e), respectively. All $J-V$ curves are reverse scan; SEM is achieved at $52^{\circ}$ tilt angle and scale bar is $250 \mathrm{~nm}$. 
(a)

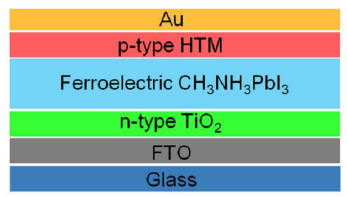

Without poling

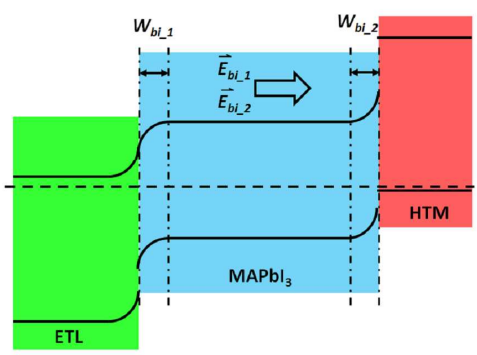

(b)
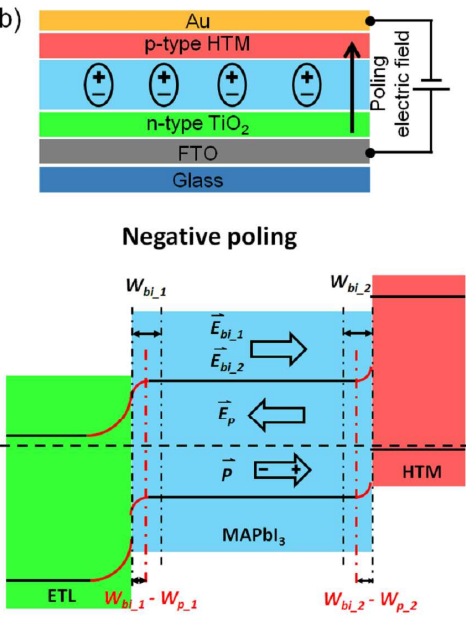

(c)
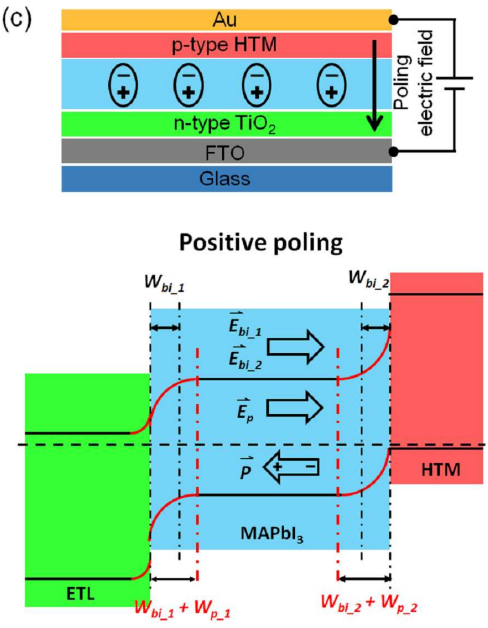

Figure 3. Schematic and band diagram of $p-F E-n$ solar cells under different poling conditions: (a) without poling, (b) negative poling, and (c) positive poling.
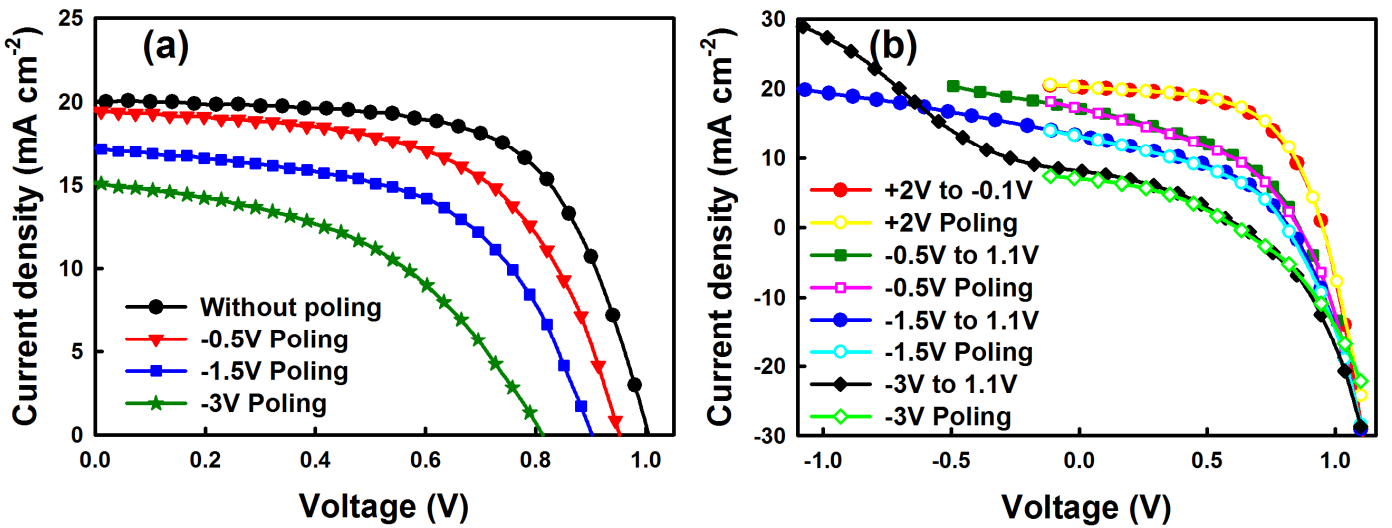

Figure 4. $J-V$ plots of mesoporous- $\mathrm{TiO}_{2}$ based $\mathrm{CH}_{3} \mathrm{NH}_{3} \mathrm{PbI}_{3}$ solar cells: (a) reverse scan at different poling voltage and (b) comparison of linear scan at large voltage region with linear scan at $-0.1 \mathrm{~V}$ to $-1.1 \mathrm{~V}$ region after poling. 

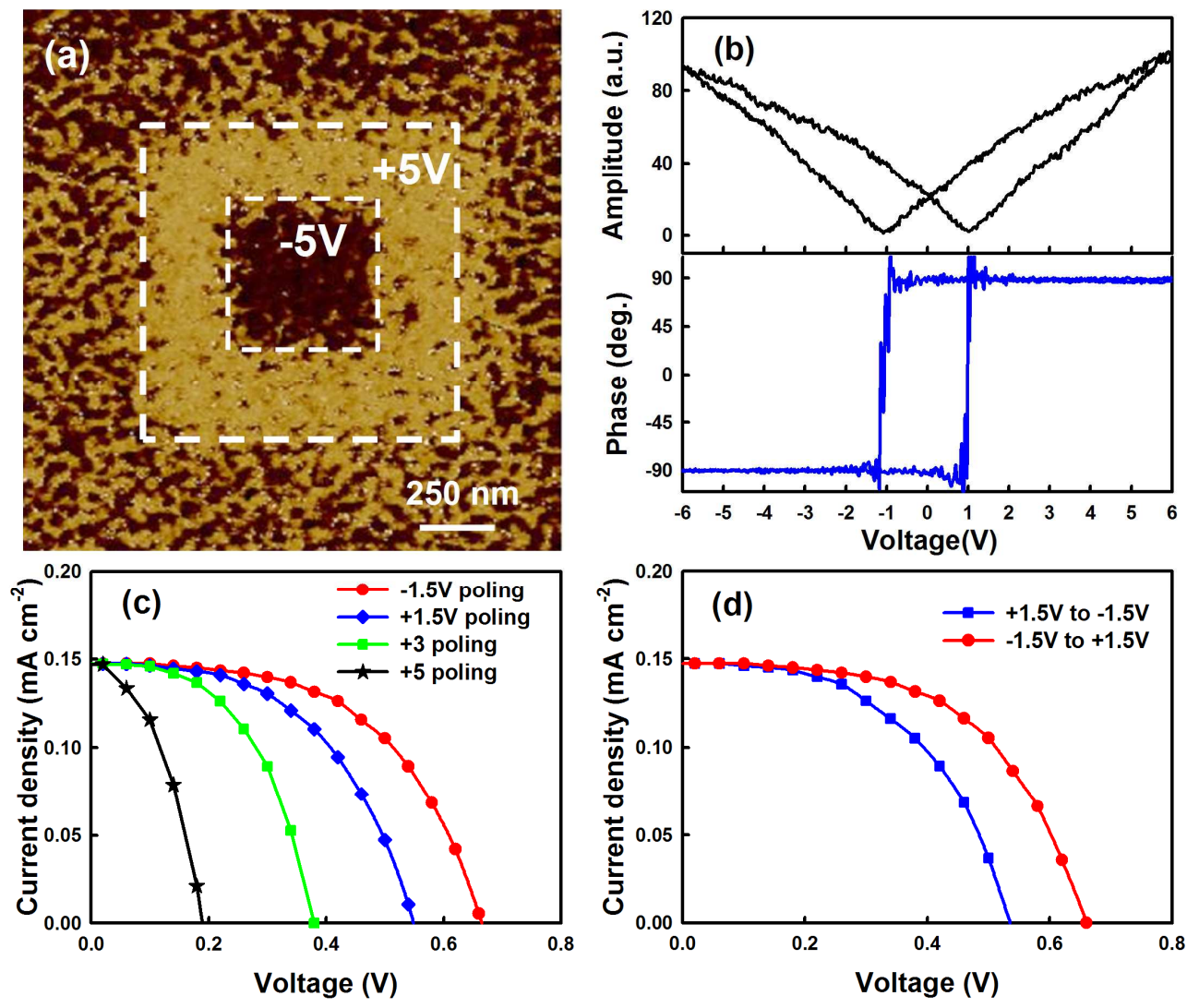

Figure 5. (a) PFM phase image for BT-BFO ferroelectric thin film with $1 \mu \mathrm{m} \times 1 \mu \mathrm{m}$ region $+5 \mathrm{~V}$ poling and $500 \mathrm{~nm} \times 500 \mathrm{~nm}$ region $-5 \mathrm{~V}$ poling. (b) Piezoresponse phase and piezoresponse amplitude at different bias voltages. (c) $J-V$ plots of BT-BFO ferroelectric solar cells at (c) different poling voltages and (d) forward and reverse scan.

\begin{tabular}{|c|c|c|c|c|c|}
\hline Cell structures & $\begin{array}{c}\text { Poling voltage } \\
\text { (V) }\end{array}$ & $\mathbf{V}_{\text {OC }}(\mathbf{V})$ & $\mathbf{J}_{\mathrm{SC}}\left(\mathbf{m A ~ c m} \mathbf{c m}^{-2}\right)$ & FF $(\%)$ & $\eta(\%)$ \\
\hline \multirow{3}{*}{$\begin{array}{l}\mathrm{mp}-\mathrm{TiO}_{2} \text { based } \\
\text { perovskite solar } \\
\text { cells (Figure } 2 \mathrm{a} \text { ) }\end{array}$} & None & 1.00 & 20.06 & 64.53 & 13.01 \\
\hline & +2 & 1.00 & 20.29 & 65.58 & 13.28 \\
\hline & -1.5 & 0.90 & 17.13 & 55.92 & 8.64 \\
\hline \multirow{3}{*}{$\begin{array}{c}\text { Planar perovskite } \\
\text { solar cells } \\
\text { (Figure } 2 \mathrm{~b})\end{array}$} & None & 1.03 & 19.96 & 65.69 & 13.47 \\
\hline & +2 & 1.03 & 20.08 & 65.54 & 13.56 \\
\hline & -1.5 & 0.95 & 18.54 & 47.23 & 8.31 \\
\hline \multirow{3}{*}{$\begin{array}{l}\text { HTM-free planar } \\
\text { perovskite solar } \\
\text { cells(Figure 2c) }\end{array}$} & None & 0.47 & 4.62 & 13.81 & 0.30 \\
\hline & +2 & 0.69 & 6.11 & 39.54 & 1.67 \\
\hline & -1.5 & 0.29 & 0.81 & 21.21 & 0.05 \\
\hline
\end{tabular}

Table 1. Photovoltaic performance of the solar cells shown in Figure 2. 


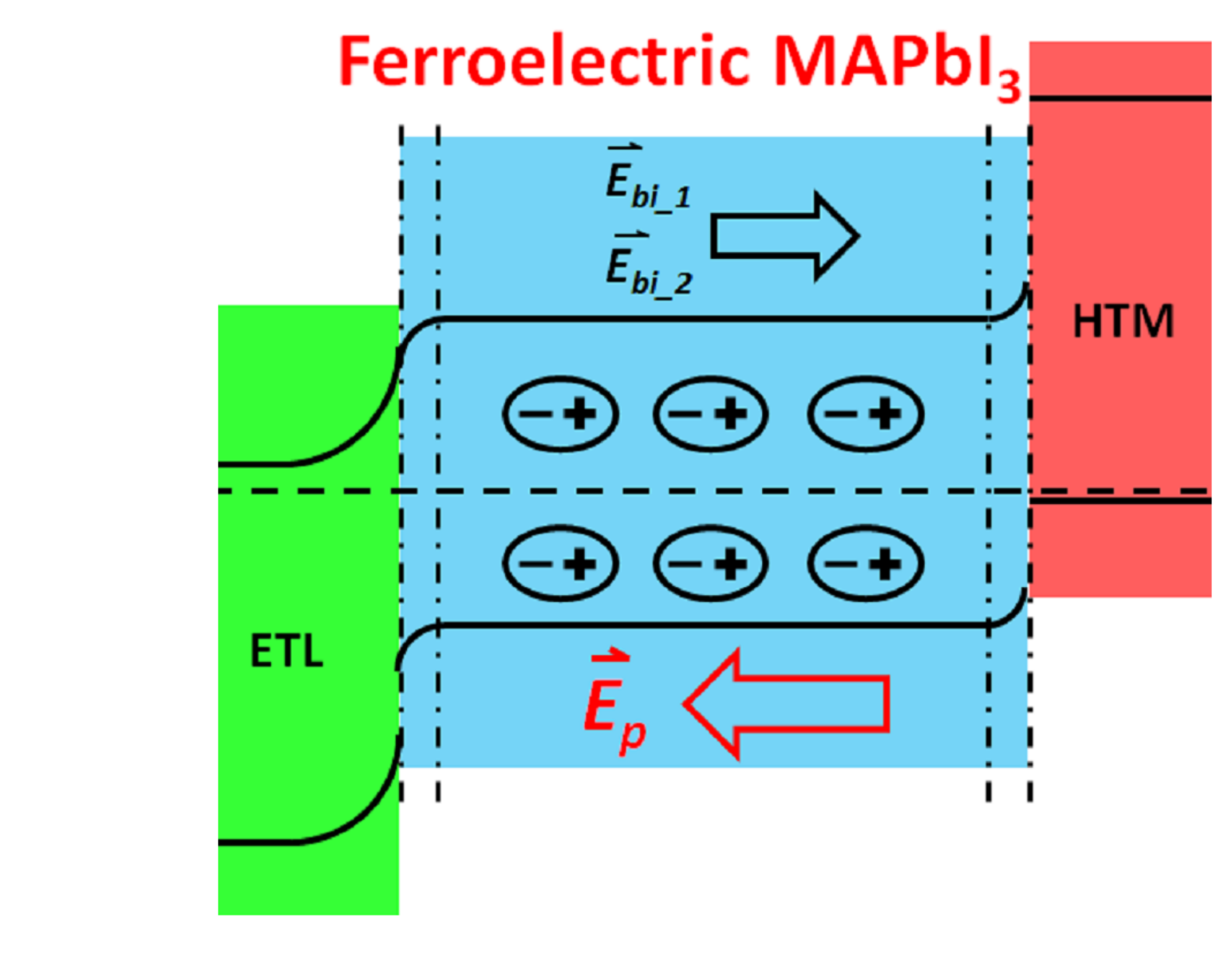

\section{Ferroelectric $\mathrm{MAPbI}_{3}$}

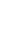
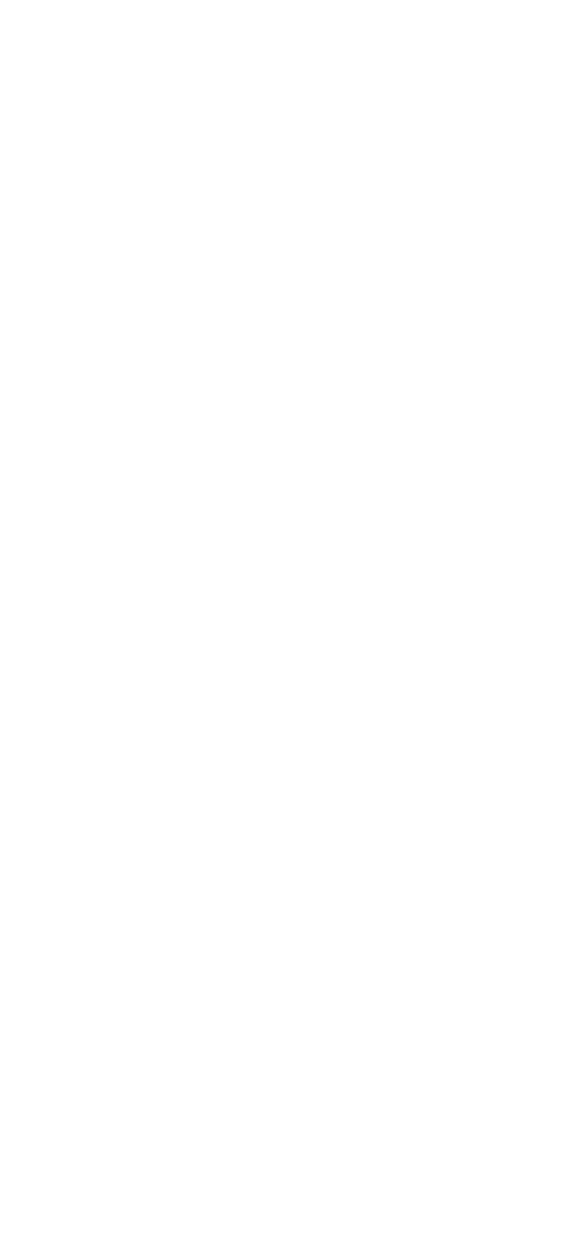